\title{
Incorporação de lodo calcinado de estação de tratamento de água como material cimentício suplementar
}

\author{
Use of calcined water treatment sludge as supplementary \\ cementitious material
}

\author{
Artur Spat Ruviaro \\ Laura Silvestro \\ Taylana Piccinini Scolaro \\ Fernando Pelisser \\ Philippe Jean Paul Gleize
}

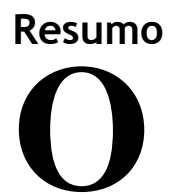

lodo de estação de tratamento de água (ETA), principal resíduo gerado pelas atividades de potabilização da água, quando calcinado possui compostos químicos semelhantes aos encontrados nas matérias-primas cimentantes, viabilizando sua utilização como material cimentício suplementar (MCS). Este trabalho teve como objetivos: a) caracterização química e física do lodo calcinado a temperatura de $700^{\circ} \mathrm{C}$ (LETAC) durante 1 hora, proveniente de uma ETA localizada em Venâncio Aires (RS);b) avaliação da influência da sua incorporação, em percentuais de $10 \%$ e $25 \%$ como MCS em pastas e em argamassas. Foram realizados ensaios microestruturais e mecânicos. Os resultados obtidos na calorimetria indicam que o resíduo apresenta efeito fíler e químico. A partir da análise termogravimétrica, verificou-se que a incorporação do lodo nas pastas de cimento promoveu um consumo de hidróxido de cálcio (redução de $40 \%$ na composição com $25 \%$ de LETAC) e consequente formação de C-S-H. Os resultados do DRX mostram que a quantidade de fases amorfas foi superior em $11 \%$ na pasta com $25 \%$ de LETAC,

${ }^{1}$ Artur Spat Ruviaro 'Universidade Federal de Santa Catarina Florianópolis - SC - Brasil

${ }^{2}$ Laura Silvestro 'Universidade Federal de Santa Catarina

Florianópolis - SC - Brasi

${ }^{3}$ Taylana Piccinini Scolaro Universidade Federal de Santa Catarina

Florianópolis - SC - Brasil

${ }^{4}$ Fernando Pelisser ${ }^{4}$ Universidade Federal de Santa Catarina

Florianópolis - SC - Brasi ${ }^{5}$ Philippe Jean Paul Gleize
${ }^{5}$ Universidade Federal de Santa
Catarina
Florianópolis - SC - Brasil

Recebido em 21/01/20 Aceito em 04/06/20 confirmando o desenvolvimento adicional de C-S-H. Quanto às propriedades mecânicas, não foram verificadas perdas significativas de resistência à compressão em pastas quando utilizado o resíduo em até $25 \%$ de substituição.

Palavras-chave: Lodo calcinado de ETA. Material pozolânico. Efeito fíler. Atividade pozolânica.

\section{Abstract}

Whensludge from water treatment plants (WTP), is calcined, ithas chemical compounds similar to those found in cementing raw materials, enabling its use as supplementary cementitious material (SCM). The aims of thisstudyare as follows: 1) chemical and physical characterisation of calcined sludge originated from a WTP located in Venâncio Aires (RS)at a temperature of $700^{\circ} \mathrm{C}($ LETAC) for 1 hour, 2) evaluation of the influence of its incorporation, in percentages of $10 \%$ and $25 \%$, as SCMin pastes and mortars. Microstructural and mechanical tests were performed. The calorimetry results indicate that the waste has a filler and chemical effect. The thermogravimetric analysisshowedthat the incorporation of sludge in cement pastes promoted the consumption of calcium hydroxide $(40 \%$ reduction in the composition with $25 \%$ of LETAC) and consequent formation of $C$ $S$ - $H$. The results of the DRX show that the amount of amorphous phases was $11 \%$ higher in the paste with $25 \%$ of LETAC, confirming the additional development of $C-S$-H. Concerningthe mechanical properties, no significant loss of compressive strength was observed in pastes when waste substitution of up to $25 \%$ wasused.

Keywords: Calcined sludge from WTP. Pozzolanic material. Filler effect. Pozzolanic activity. 


\section{Introdução}

O consumo elevado de cimento Portland pode ser associado a fatores como baixo custo, matéria-prima abundante e resultados satisfatórios relacionados à durabilidade de estruturas constituídas por esse material. No ano de 2016 a produção mundial de clínquer foi de 6,06 bilhões de toneladas. No Brasil, de 1990 a 2016 , essa produção aumentou de 18,7 para 38,8 milhões de toneladas (WORLD..., 2016). Nesse contexto, o alto consumo de cimento Portland está vinculado a um grande impacto ambiental, uma vez que a sua produção envolve elevada emissão de gás carbônico $\left(\mathrm{CO}_{2}\right)$. Uma alternativa para a redução das emissões de $\mathrm{CO}_{2}$ consiste na substituição parcial do cimento Portland por materiais cimentícios suplementares (MCS). Entre 1990 e 2016, a incorporação de materiais pozolânicos para a produção de clínquer no Brasil aumentou de 93,2 para 715 mil toneladas (WBCSD, 2016), evidenciando a tendência da utilização de MCS. Isso posto, de acordo com Gastaldini et al. (2015), as indústrias modernas de cimento já reduziram a emissão de $\mathrm{CO}_{2}$ para 0,7 tonelada para cada tonelada de clínquer produzido. No entanto, segundo Hagemann et al. (2019), a implementação de muitas dessas novas iniciativas nem sempre é viável, devido a dificuldades e adaptações técnicas e operacionais ou à falta de regulamentação e normalização, de modo que o uso de MCS continua sendo a principal alternativa para reduzir o consumo de cimento Portland.

Entre os MCS, destacam-se as pozolanas naturais. As pozolanas reagem quimicamente com o hidróxido de cálcio para produzir compostos com propriedades cimentantes. Existem extensas reservas de pozolanas naturais em todo o mundo, entretanto estas geralmente têm reatividade muito baixa e suas características são variáveis de acordo com sua localização.

Nesse contexto, e considerando as propriedades químicas e físicas do lodo de estação de tratamento de água (ETA), alternativas para a aplicação desse material na produção de materiais de construção, tais como telhas, agregados leves, concretos e geopolímeros, vêm sendo amplamente pesquisadas (GOMES et al., 2019). As principais composições químicas de alguns lodos residuais contêm $\mathrm{Al}_{2} \mathrm{O}_{3}, \mathrm{Fe}_{2} \mathrm{O}_{3}$ e $\mathrm{SiO}_{2}$, que são os principais compostos químicos das matérias-primas cimentícias.O lodo de ETA, resultado do processo de transformação de água bruta em água potável nas estações de tratamento de água, é classificado como resíduo sólido pertencente à Classe II A (resíduos não inertes), de acordo com a NBR 10004 (ABNT, 2004). Essa classe de resíduos não pode ser lançada na rede pública de esgoto nem em corpos d'água, sendo comumente disposta em aterros sanitários, gerando elevados custos de destinação para as empresas geradoras (COCCO, 2017). Como agravante, elevadas quantidades de lodo de ETA são produzidas diariamente (GOMES et al., 2019). Estima-se que em uma ETA usual, caracterizada pelos processos de coagulação, floculação, sedimentação, filtração e desinfecção, são geradas cerca de 100.000 toneladas/ano de lodo de ETA (AHMAD; AHMAD; ALAM, 2016).

Gomes et al. (2019) realizaram um levantamento na literatura existente, identificando a quantidade de lodo de ETA per capita gerada em diversos países. Portugal apresenta o maior per capita, com um valor de 6,42 toneladas/ano. Países como China, Japão, Alemanha, França e Austrália apresentam um per capita de, respectivamente, 1,06, 2,28, 1,48, 2,59, 0,98 e 1,75 toneladas de lodo de ETA por ano. No Brasil, estima-se que o volume diário de lodo gerado em uma estação de tratamento varia entre $0,1 \%$ e $3 \%$ em relação ao volume diário de água tratada (BERNARDO; DANTAS; VOLTAN, 2012). De acordo com Tartari (2008), em termos volumétricos, a maior quantidade de resíduos gerados é proveniente da água de lavagem de filtros, mas em termos de massa, as maiores quantidades são provenientes dos decantadores.

Recentemente, alguns pesquisadores têm se dedicado ao estudo do lodo de ETA calcinado como material cimentício suplementar. Godoy et al. (2019) realizaram a caracterização de um lodo de uma estação de tratamento de água localizada no sul do Brasil. Os autores verificaram que a temperatura de calcinação influencia na reatividade do resíduo. O lodo de ETA calcinado a uma temperatura de $600{ }^{\circ} \mathrm{C}$ resultou em um MCS equivalente a uma pozolana normal, já o material submetido à calcinação em uma temperatura de 750 ${ }^{\circ} \mathrm{C}$ resultou em uma pozolana de alta reatividade.

Ahmad, Ahmad e Alam (2016) mencionam que existe uma carência de pesquisas sobre a resistência à compressão de cimentos com a incorporação de lodo de ETA, e que tal fato gera limitações no que tange à aplicação prática. Nesse âmbito, El-Didamony, Khalil e Heikal (2014) substituíram em cimentos compostos a quantidade de escória granulada de alto forno por percentuais de lodo de ETA de 5\%, 10\% e $15 \%$. Os autores observaram que as pastas de cimento com a substituição de escória por lodo de ETA apresentaram um aumento da água quimicamente combinada e de produtos de hidratação e, consequentemente, incrementos na resistência à compressão de até $5 \%$ com percentuais de substituição de 5\% de lodo de ETA. Esse comportamento é atribuído ao efeito de nucleação do lodo de ETA e à atividade pozolânica superior à escória granulada de alto forno utilizada. 
Gastaldini et al. (2015) avaliaram a resistência à compressão de concretos com teores de substituição de cimento Portland por lodo calcinado de ETA variando entre $0 \%$ e $30 \%$. A incorporação do resíduo resultou em um aumento nos valores de resistência à compressão, nas idades de 7 e 28 dias, com acréscimos de resistência entre $3 \%$ e $30 \%$.

Stein (2016) avaliou características microestruturais de pastas de cimento Portland com teores de substituição de cimento por lodo calcinado de ETA de 0\%, 5\%, 10\%, 15\%, 20\%, 25\% e 30\%. Os resultados obtidos pelo autor indicaram que, com um aumento do teor de substituição de cimento por resíduo, houve uma redução na concentração de hidróxido de cálcio, o que está relacionado com a formação de C-S-H, confirmando a atividade pozolânica desse resíduo.

Entretanto, Rodríguez et al. (2010), substituindo parcialmente o cimento Portland por percentuais de lodo de ETA de 10\%, $20 \%$ e 30\% em argamassas, verificaram retardos expressivos nas taxas de hidratação, bem como reduções nas resistências à compressão aos 28 dias em relação ao traço de controle, com índices de atividade pozolânica entre $30 \%$ e $50 \%$. Isso, de acordo com os autores, ocorreu porque, embora a proporção de $\mathrm{SiO}_{2}+\mathrm{Al}_{2} \mathrm{O}_{3}$ do lodo de ETA seja elevada, a sua estrutura é predominantemente cristalina e não exibiu atividade pozolânicano ensaio químico de Frattini. Segundo Tironi et al. (2013), a elevada superfície específica das argilas calcinadas tem mais efeito sobre a atividade pozolânica em curto prazo, enquanto que em longo prazo a atividade pozolânica está relacionada com a composição mineralógica e química das fases amorfas das argilas calcinadas.

Diante do exposto, este trabalho realizou a caracterização de um resíduo proveniente de uma planta de estação de tratamento de água localizada no município de Venâncio Aires (Rio Grande do Sul) e investigou o potencial do uso desse lodo de ETA calcinado como MCS. Dessa maneira, o estudo contribui para encontrar uma alternativa tecnicamente viável para o lodo de ETA, evitando assim que tal resíduo seja descartado de maneira inadequada em rios e reduzindo a área necessária para a disposição desse material em aterros sanitários. Além disso, conforme mencionado por Godoy et al. (2019), são escassos os trabalhos que utilizaram lodo de ETA localizadas no sul do Brasil como matéria-prima para a produção de materiais cimentícios suplementares. Os autores também destacam a importância da caracterização de lodos de ETA de diferentes locais para garantir que as propriedades do material calcinado possibilitem sua utilização como MSC, uma vez que a composição e as características químicas e físicas do lodo gerado variam de acordo com a localização da ETA. Por fim, destaca-se que não foram encontrados trabalhos na literatura que avaliaram a influência da incorporação de lodo de ETA calcinado na resistência à tração na flexão de argamassas, o que ressalta o ineditismo do trabalho em questão.

\section{Materiais e métodos}

\section{Materiais}

Nesta pesquisa foi utilizado o cimento Portland CP V-ARI, conforme a NBR 16697 (ABNT, 2018), equivalente ao cimento Tipo III especificado pela C150/C150M (AMERICAN..., 2018). A composição química é apresentada na Tabela 1 e as principais características físicas e mecânicas desse cimento estão apresentadas na Tabela 2.

Tabela 1 - Caracterização química do cimento Portland CP V - ARI

\begin{tabular}{c|c}
\hline CARACTERIZACÃO OUÍMICA & RESULTADOS \\
\hline $\mathrm{Al}_{2} \mathrm{O}_{3}$ & 4,38 \\
$\mathrm{SiO}_{2}$ & 18,91 \\
$\mathrm{Fe}_{2} \mathrm{O}_{3}$ & 2,91 \\
$\mathrm{CaO}$ & 61,19 \\
$\mathrm{MgO}$ & 3,54 \\
$\mathrm{SO}_{3}$ & 3,14 \\
Perda ao fogo & 3,41 \\
$\mathrm{CaO}$ livre & 0,84 \\
Resíduo insolúvel & 0,84 \\
\hline
\end{tabular}

Fonte: relatório do fabricante, Lafarge Holcim (2018). 
Tabela 2 -Caracterização física e mecânica do cimento Portland CP V - ARI

\begin{tabular}{c|c}
\hline CARACTERIZACÃO FÍSICA & RESULTADOS \\
\hline Massa específica $\left(\mathrm{g} / \mathrm{cm}^{3}\right)$ & 3,09 \\
Blaine $\left(\mathrm{cm}^{2} / \mathrm{g}\right)$ & 4608 \\
Tempo de início de pega $(\mathrm{min})$ & 135 \\
Tempo de fim de pega $(\mathrm{min})$ & 190 \\
Finura peneira \#200 $(\%)$ & 0,08 \\
Expansibilidade $(\mathrm{mm})$ & 0,32 \\
Resistência à compressão 1 dia $(\mathrm{MPa})$ & 28,35 \\
Resistência à compressão 3 dias $(\mathrm{MPa})$ & 42,46 \\
Resistência à compressão 7 dias $(\mathrm{MPa})$ & 47,78 \\
Resistência à compressão 28 dias $(\mathrm{MPa})$ & 54,41 \\
\hline
\end{tabular}

Fonte: relatório do fabricante, Lafarge Holcim (2018).

\section{Preparo e caracterização do lodo de ETA calcinado}

O lodo de estação de tratamento de água utilizado nesta pesquisa é proveniente da ETA do município de Venâncio Aires, Rio Grande do Sul, onde o abastecimento é realizado pela Companhia Riograndense de Saneamento (CORSAN). A água tratada na ETA é proveniente do Arroio Castelhano. O material in natura foi previamente seco em estufa, a uma temperatura de $60 \pm 5{ }^{\circ} \mathrm{C}$, e cominuído manualmente com uma marreta. Posteriormente, o lodo foi calcinado em uma mufla Linn Elektro Therm GmbH, modelo KK260.

Para determinação da temperatura de calcinação do lodo de estação de tratamento de água calcinado (LETAC), foi realizado o ensaio de termogravimetria. A análise termogravimétrica (TG) foi realizada no equipamento SDT Q600 da TA Instruments. A amostra foi aquecida até uma temperatura de aproximadamente $1.000^{\circ} \mathrm{C}$, com uma taxa de aquecimento de $20{ }^{\circ} \mathrm{C} / \mathrm{min}$ e um fluxo de $\mathrm{N}_{2}$ de $100 \mathrm{ml} / \mathrm{min}$.

A Figura 1 apresenta os resultados da análise termogravimétrica(TGA) e a curva de calorimetria exploratória diferencial (DSC) do lodo de ETA in natura. A partir da curva DSC é possível identificar diferentes fenômenos que ocorrem na amostra de lodo de ETA devido ao aquecimento. O primeiro pico é exotérmico e associado à perda de água livre e/ou absorvida(KIZINIEVIČ et al., 2013). O segundo pico é endotérmico e está relacionado à decomposição da matéria orgânica (KIZINIEVIČ et al., 2013; MONTEIRO et al., 2008). $\mathrm{O}$ terceiro picoexotérmico na faixa de temperatura de $470{ }^{\circ} \mathrm{C}$ a $510{ }^{\circ} \mathrm{C}$ está relacionado àdesidroxilação de minerais argilosos (MONTEIRO et al., 2008). O último pico endotérmico próximo dos $900{ }^{\circ} \mathrm{C}$ está associado à recristalização do material. Os resultados encontrados corroboram com os encontrados na pesquisa de Hagemann et al. (2019).

A temperatura de calcinação escolhida de $700{ }^{\circ} \mathrm{C}$ garante a desidroxilação completa e está bem abaixo da temperatura de recristalização como pode ser observado na Figura 1. Ainda em análise a Figura 1, observase que não ocorreu perda de massa remanescente significativa, confirmando que a desidroxilação foi totalmente concluída na temperatura de $700{ }^{\circ} \mathrm{C}$. A perda de massa $\left(105{ }^{\circ} \mathrm{C}-1.000{ }^{\circ} \mathrm{C}\right)$ foi de $12,15 \%$ e $2,63 \%$, respectivamente, para o lodo in natura e para o LETAC, determinada através da termogravimetria.

O processo de calcinação compreendeu três etapas: período de aquecimento $\left(10{ }^{\circ} \mathrm{C} / \mathrm{min}\right)$ até atingir $700{ }^{\circ} \mathrm{C}$, patamar de temperatura constante a $700{ }^{\circ} \mathrm{C}$ com duração de 1 hora e resfriamento lento, em que o material foi deixado descansar dentro da mufla desligada até atingir a temperatura ambiente. Após, procedeu-se à moagem do lodo calcinado em moinho de bolas AMEF, modelo AMBI 480 X 400. A moagem foi feita em lotes de 2,0kg do material. Cada lote do material foi moído por 60 minutos em velocidade angular lenta.

A caracterização do LETAC foi realizada através dos ensaios: fluorescência de raios X (FRX) para determinação da composição química do resíduo, BET para determinação da área superficial, difração de raios X (DRX) para avaliar o grau de amorficidade do material, granulometria a laser para verificar a distribuição e o tamanho das partículas e microscopia eletrônica de varredura (MEV) para avaliar a morfologia da partícula. A composição química do LETAC foi determinada por meio da análise quantitativa, em um espectrômetro por fluorescência de raiosX EDX-7000, marca Shimadzu. Para determinação da área superficial foi utilizado o equipamento Quantachrome Instruments - Autosorb - 1. O ensaio de DRX foi realizado em um equipamento da marca Rigaku, modelo Miniflex II, com geometria $\theta-2 \theta$, raios X Cu / 30 $\mathrm{kV} / 15 \mathrm{~mA}$ e alcance angular de $3^{\circ}-90^{\circ}$. A amorficidade do resíduo foi avaliada através do software X'PertHighScore Plus (da PANalytical). O procedimento consiste em quantificar a área sobre a curva do difratograma, identificando assim o percentual de amorfo e de material cristalino. A análise de distribuição 
do tamanho de partícula do LETAC foi realizada em um granulômetro a laser Microtrac S3500, sem meio dispersante e com intervalo de análise de $0,243 \mu \mathrm{m}$ a $1408 \mu \mathrm{m}$. Por fim, as micrografias das pastas foram obtidas em um microscópio SM-6390LV (JEOL), operando com energia de $10 \mathrm{kV}$ e, previamente ao ensaio, as amostras foram recobertas com ouro.

\section{Composições}

As composições avaliadas nesta pesquisa estão apresentadas na Tabela 3.

Para melhor elucidar o programa experimental, na Figura 2 é apresentado um fluxograma com os ensaios realizados em pastas e em argamassas. Além dos ensaios apresentados no fluxograma da Figura 2, também foi realizado o ensaio de índice de atividade pozolânica com cimento Portland de acordo com a NBR 5752 (ABNT, 2014).

Figura 1 - Análise termogravimétrica do lodo de ETA in natura

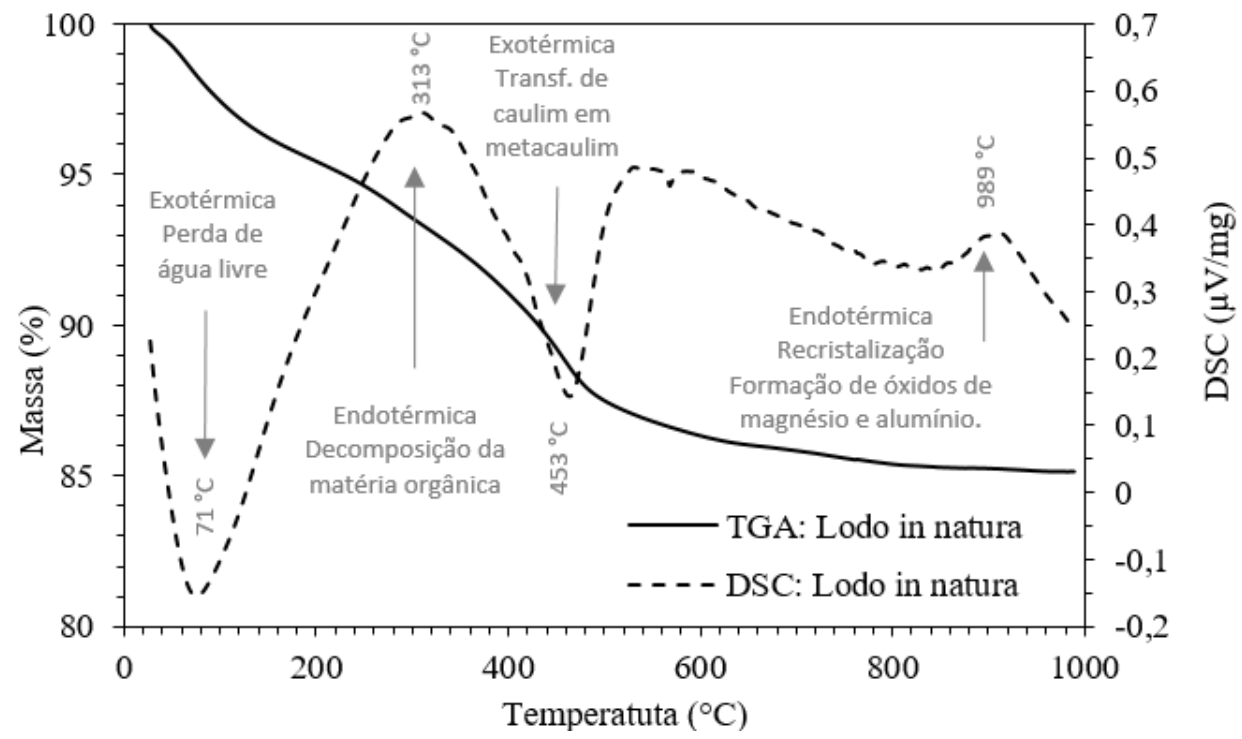

Tabela 3 - Denominação das composições avaliadas

\begin{tabular}{l|c|c|c|c|c|c}
\hline \multicolumn{1}{c|}{ Denominação } & AC4L0 & AC4L10 & AC4L25 & AC6L0 & AC6L10 & AC6L25 \\
\hline $\begin{array}{l}\text { Percentual de LETAC em } \\
\text { substituição ao cimento (\%) }\end{array}$ & 0 & 10 & 25 & 0 & 10 & 25 \\
\hline Relação água/aglomerante & 0,4 & 0,4 & 0,4 & 0,6 & 0,6 & 0,6 \\
\hline
\end{tabular}

Figura 2 - Fluxograma dos ensaios realizados em: pastas e argamassas

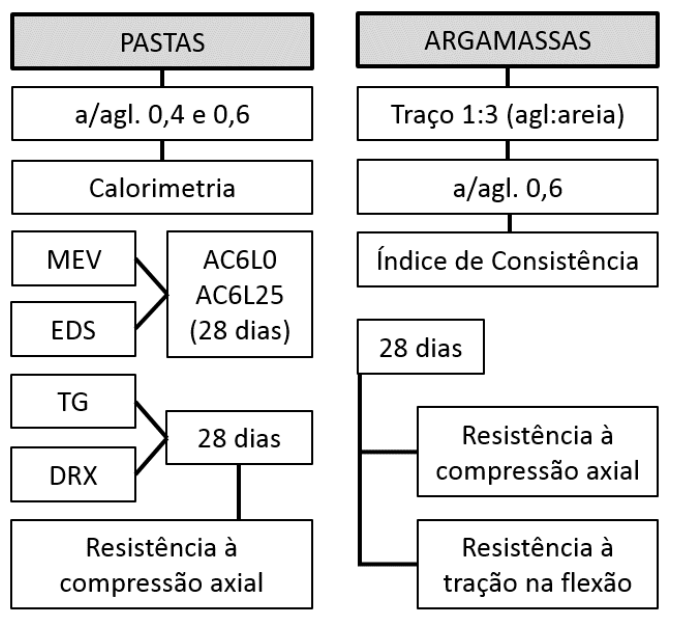




\section{Procedimento de mistura}

Para a produção das pastas, o cimento e o lodo de ETA calcinado foram previamente homogeneizados por um período de 2 minutos. Posteriormente, os materiais secos foram colocados no misturador e a água foi adicionada, dando-se início ao processo de mistura. Para as pastas, foi utilizado um agitador mecânico a $1.600 \mathrm{rpm}$ durante $2 \mathrm{~min}$, seguindo o mesmo procedimento adotado por Berodier e Scrivener (2015).

As argamassas foram produzidas considerando uma proporção de aglomerante:areia de 1:3. Nesse caso foi utilizada a areia normal, em conformidade com a norma NBR 7214 (ABNT, 2015b), e a mistura dos materiais foi realizada de acordo com o procedimento descrito na NBR 7215 (ABNT, 2019).

\section{Métodos}

\section{Avaliação da cinética de hidratação}

A cinética de hidratação das misturas foi avaliada por calorimetria isotérmica em um calorímetro Thermometric AB da TAM Air da TA Instruments. Nos traços compostos por cimento e lodo de ETA calcinado, os materiais em pó foram previamente homogeneizados durante 1 minuto. Posteriormente, foi adicionada água e, após mistura externa manual por um período de 2 minutos, as amostras foram inseridas no calorímetro. A liberação de calor foi registrada a uma temperatura de $23^{\circ} \mathrm{C}$ durante 65 horas.

\section{Análise termogravimétrica}

A análise termogravimétrica das pastas de cimento (AC6L0, AC6L10 e AC6L25) foi realizada no equipamento SDT Q600 da TA Instruments. As amostras foram aquecidas até uma temperatura de aproximadamente $1.000{ }^{\circ} \mathrm{C}$, com uma taxa de aquecimento de $20^{\circ} \mathrm{C} / \mathrm{min}$ e um fluxo de $\mathrm{N}_{2}$ de $100 \mathrm{ml} / \mathrm{min}$. As amostras foram analisadas aos 28 dias de idade. Inicialmente, as pastas de cimento foram moídas manualmente em um almofariz de ágata e o material utilizado na análise foi o passante na peneira \#200.

$\mathrm{O}$ teor de hidróxido de cálcio $\left(\mathrm{Ca}(\mathrm{OH})_{2}\right)$ foi calculado de acordo com a Equação 1, considerando que a decomposição desse composto geralmente ocorre na faixa de temperatura de $400{ }^{\circ} \mathrm{C}-500^{\circ} \mathrm{C}$. Para o cálculo previamente mencionado, as perdas de massa das amostras foram normalizadas em relação à massa de cimento anidro, adotada neste trabalho como a massa das amostras na temperatura de $600{ }^{\circ} \mathrm{C}$ (SCRIVENER; SNELLINGS; LOTHENBACH, 2016).

$\mathrm{Ca}(\mathrm{OH})_{2}=\mathrm{WL}_{\mathrm{Ca}(\mathrm{OH})_{2}} \times \frac{\mathrm{m}_{\mathrm{Ca}(\mathrm{OH})_{2}}}{\mathrm{~m}_{\mathrm{H}_{2} \mathrm{O}}}$ Eq. 1

Onde:

$\mathrm{Ca}(\mathrm{OH})_{2}$ - Teor de hidróxido de cálcio $(\%)$;

$\mathrm{WL}_{\mathrm{Ca}(\mathrm{OH})_{2}}$ - Perda de massa do hidróxido de cálcio;

$\mathrm{m}_{\mathrm{Ca}(\mathrm{OH})_{2}}$ - Massa molar do hidróxido de cálcio $(74 \mathrm{~g} / \mathrm{mol}) ; \mathrm{e}$

$\mathrm{m}_{\mathrm{H}_{2} \mathrm{O}}$ - Massa molar da água $(18 \mathrm{~g} / \mathrm{mol})$.

\section{Difração de raios $X$}

O ensaio de DRX foi realizado nas pastas com relação a/ag=0,6 (AC6L0, AC6L10 e AC6L25) aos 28 dias, sendo utilizados os fragmentos moídos dos corpos de prova ensaiados à resistência à compressão, retirados da parte interior dos corpos de prova. Cada composição teve seus fragmentos moídos à mão, com o auxílio de um almofariz de ágata, e posteriormente passados na peneira de malha $75 \mu \mathrm{m}$. O equipamento utilizado na análise é da marca Rigaku, modelo Miniflex II, com geometria $\theta-2 \theta$, raios X Cu / $30 \mathrm{kV} / 15 \mathrm{~mA}$ e alcance angular de $3^{\circ}-90^{\circ}$.

A amorficidade das pastas foi avaliada através do software X'PertHighScore Plus (da PANalytical). O procedimento consiste em quantificar a área sobre a curva do difratograma, identificando assim o percentual de amorfo e de material cristalino.

\section{Microscopia eletrônica de varredura}

Duas amostras (AC6L0 e AC6L25) foram extraídas da parte interna dos corpos de prova rompidos no ensaio mecânico e colocadas em estufa para secagem por 24 horas a $60{ }^{\circ} \mathrm{C}$. Posteriormente, as amostras foram 
recobertas por uma fina camada de ouro e mantidas em um dessecador com vácuo até a realização do ensaio. As micrografias das pastas foram obtidas em um microscópio SM-6390LV (JEOL), operando com energia de $10 \mathrm{kV}$. Com vistas a complementar os resultados, foi realizada a espectrometria de dispersão de energia (EDS), de modo a identificar os elementos químicos presentes.

\section{Índice de atividade pozolânica (IAP)}

O ensaio foi realizado de acordo com a NBR 5752 (ABNT, 2014). Foram produzidas 2 argamassas A e B, ambas com proporção $1: 3$ e relação a/c de 0,48 . Como relação ao material aglutinante, a argamassa A é composta por $100 \%$ de cimento Portland CPII-F-32 e a B por $75 \%$ de CPII-F-32 e $25 \%$ de LETAC (substituições em massa). O IAP é a relação entre a resistência média da argamassa A pela resistência média da argamassa B aos 28 dias, multiplicando por 100. Foram moldados 4 corpos de prova para cada argamassa.

\section{Ensaios mecânicos}

O ensaio de resistência à compressão em pasta foi realizado em corpos de prova cilíndricos com dimensões de $\varnothing 20 \mathrm{~mm}$ x $40 \mathrm{~mm}$, que foram retificados em uma cortadeira metalográfica, da marca Bluehler, com um disco de corte diamantado e ensaiadas em uma prensa universal da marca Instron, modelo 5569, com uma escala de velocidade de 0,005 a $5 \mathrm{~mm} / \mathrm{min}$, de acordo com o que estabelece a norma C-1231 (AMERICAN..., 2010), que determina uma taxa de carregamento de $0,50 \mathrm{MPa} / \mathrm{s}$.

Os corpos de prova de argamassa destinados ao ensaio de resistência à compressão possuem diâmetro de 50 $\mathrm{mm}$ e altura de $100 \mathrm{~mm}$ e foram capeados antes do rompimento. Para cada traço avaliado foram moldados quatro corpos de prova. O ensaio foi realizado em uma prensa da marca Solotest.

Em relação ao ensaio de resistência à tração na flexão, os corpos de prova $4 \mathrm{~cm} \mathrm{x4} \mathrm{cm} \mathrm{x16cm,} \mathrm{foram}$ moldados seguindo a NBR 13279 (ABNT, 2005). O ensaio foi realizado em prensa da marca Solotest. Para cada traço foram moldados três corpos de prova.

Todas as amostras destinadas aos ensaios mecânicos foram submetidas a cura submersa em água saturada com cal até a idade do ensaio (28 dias).

Por fim, foi realizada análise de variância de médias (ANOVA) de maneira a determinar se as diferenças e os efeitos são significativos para os resultados, considerando intervalo de confiança de 95\%. Para tal, foi utilizado o programa Statistica 7.0 da Statsoft.

\section{Resultados e discussão}

\section{Caracterização do lodo de ETA calcinado}

Os resultados da caracterização do lodo de ETA calcinado são apresentados na Tabela 4. Verifica-se que o material é predominantemente composto por $\mathrm{SiO}_{2}, \mathrm{Al}_{2} \mathrm{O}_{3}$ e $\mathrm{Fe}_{2} \mathrm{O}_{3}$. A composição química doLETAC é semelhante à encontrada por Gastaldini et al. (2015) e Nimwinya et al. (2016), sendo que os autores calcinaram o material a uma temperatura de $600{ }^{\circ} \mathrm{C}$. Além disso, o lodo de ETA calcinado apresentou área superficial de $43,77 \mathrm{~m}^{2} / \mathrm{g}$.

Nesse contexto, a NBR 12653 (ABNT, 2015a) estabelece, para a classe N de material pozolânico, os requisitos químicos: $\mathrm{SiO}_{2}+\mathrm{Al}_{2} \mathrm{O}_{3}+\mathrm{Fe}_{2} \mathrm{O}_{3} \geq 70 \%$ e $\mathrm{SO}_{3} \leq 4 \%$; perda ao fogo $\leq 10 \%$ e álcalis disponíveis em $\mathrm{Na}_{2} \mathrm{O} \leq 1,5 \%$. O lodo in natura apresenta um somatório de 82,05\% de $\mathrm{SiO}_{2}, \mathrm{Al}_{2} \mathrm{O}_{3}$ e $\mathrm{Fe}_{2} \mathrm{O}_{3}$, enquanto o LETAC, 95,84\%.Assim, constata-se que o material atende a todos os requisitos normativos previamente apresentados, o que indica seu potencial para ser utilizado como material pozolânico.

O difratograma do LETAC é apresentado na Figura 3. Constata-se que o material é composto predominantemente por quartzo, caulinita, feldspato e hematita. Em materiais cimentícios suplementares, as fases amorfas são geralmente mais reativas e presentes do queas fases cristalinas. A amorficidade do material pode ser relacionada com o seu desempenho pozolânico, conforme apontam alguns estudos (STEIN, 2016; JUENGER; SIDDIQUE, 2015), ou seja, quanto maior a porcentagem de fases amorfas, maior é a atividade pozolânica do material. Diante disso, o difratograma do LETAC (Figura 3) apresenta um percentual de aproximadamente $57 \%$ de fases amorfas.

$\mathrm{Na}$ Tabela 5 são apresentados os resultados da granulometria do resíduo e do cimento. Os valores representam a média de três leituras. Verifica-se que o tamanho médio das partículas do resíduo é próximo 
do cimento. É importante destacar a importância de um diâmetro adequado dos materiais cimentícios suplementares para que estes apresentem reatividade e ação física, atuando também como fíler.

Na Figura 4 pode ser observada uma micrografia do resíduo. Nota-se que as partículas do lodo de ETA calcinado apresentaram formatos irregulares, com partículas de vários tamanhos e texturas rugosas. É possível também observar alguns aglomerados de partículas muito pequenas.

A Tabela 6 mostra os resultados da EDS da região indicada na Figura 4. Por meio de uma análise qualitativa, observa-se que o LETAC apresenta uma clara predominância de sílica, alumínio e ferro, coincidindo com a caracterização química realizada por FRX apresentada na Tabela 4.

\section{Índice de atividade pozolânica (IAP)}

Na Tabela 7 são apresentados os resultados médios do índice de consistência (IC), resistência à compressão (RC) axial aos 28 dias das argamassas A e B e o percentual de aditivo superplastificante (SP) utilizado na argamassa com $25 \%$ de LETAC.

A partir dos dados de resistência à compressão apresentados na Tabela 7, o IAP calculado para o LETAC foi de 114\%. A análise do resultado do IAP mostra que mesmo com 25\% de material pozolânico (LETAC) os valores obtidos são superiores aos da mistura de referência (argamassa A).

\section{Avaliação da cinética de hidratação}

As curvas de hidratação das amostras, obtidas através do ensaio de calorimetria isotérmica, são apresentadas pela Figura 5.

Tabela 4 - Composição química do lodo de ETA calcinado a uma temperatura de $700{ }^{\circ} \mathrm{C}$

\begin{tabular}{c|c|c|c|c|c|c|c|c|c|c}
\hline Composicão & $\mathbf{S i O}_{2}$ & $\mathbf{A l}_{2} \mathbf{O}_{3}$ & $\mathbf{F e}_{2} \mathbf{O}_{3}$ & $\mathbf{C a O}$ & $\mathbf{S O}_{3}$ & $\mathbf{K}_{2} \mathbf{O}^{*}$ & $\mathbf{M n O}$ & $\mathbf{T i O}_{2}$ & $\mathbf{P}_{2} \mathbf{O}_{5}$ & Área \\
\hline$\%$ & 66,93 & 17,90 & 11,01 & 0,74 & 0,26 & 1,35 & 0,17 & 1,10 & 0,36 & 43,77 \\
\hline
\end{tabular}

Nota: *álcalis encontrados nas amostras.

Figura 3 -Difratograma de raiosX da amostra do LETAC, à temperatura de $700^{\circ} \mathrm{C}$

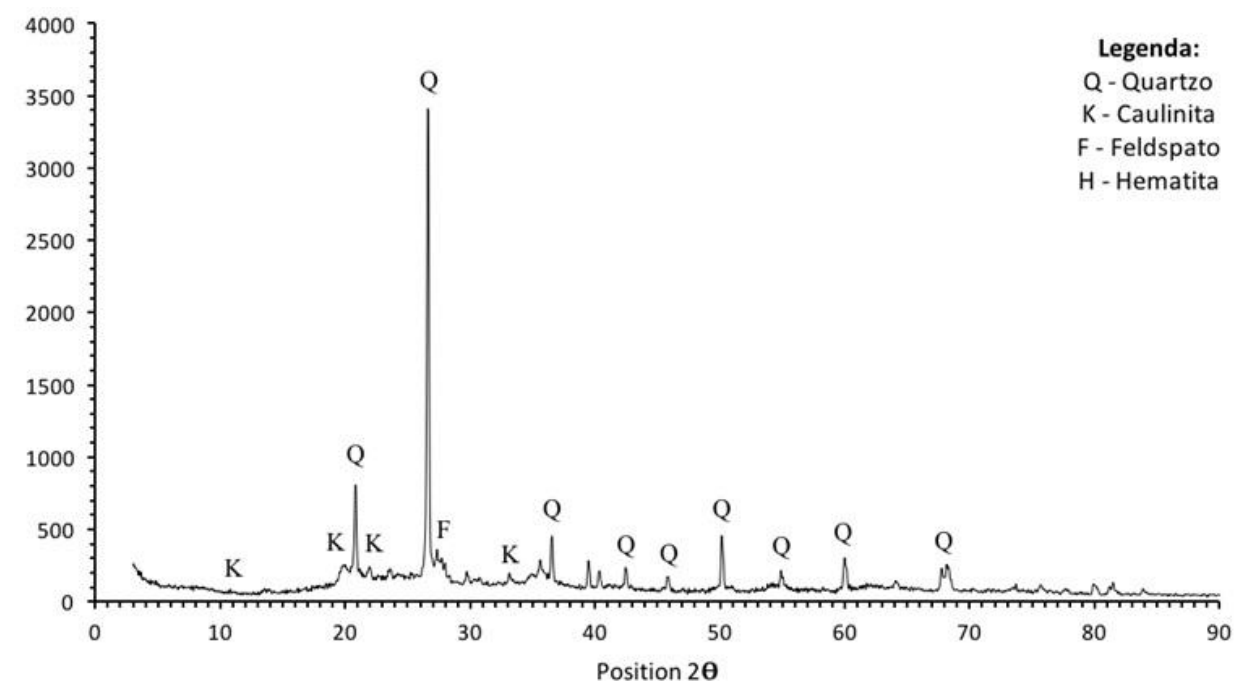

Tabela 5 - Distribuição do tamanho de partícula do cimento Portland CP V - ARI e do LETAC

\begin{tabular}{c|c|c}
\hline DIÂMETRO DAS PARTÍCULAS & CIMENTO PORTLAND & LODO DE ETA CALCINADO \\
\hline d10 & 2,80 & 1,29 \\
d50 & 16,56 & 18,67 \\
d90 & 40,95 & 72,51 \\
Média & 21,09 & 30,08 \\
\hline
\end{tabular}


Figura 4 - Micrografia do LETAC

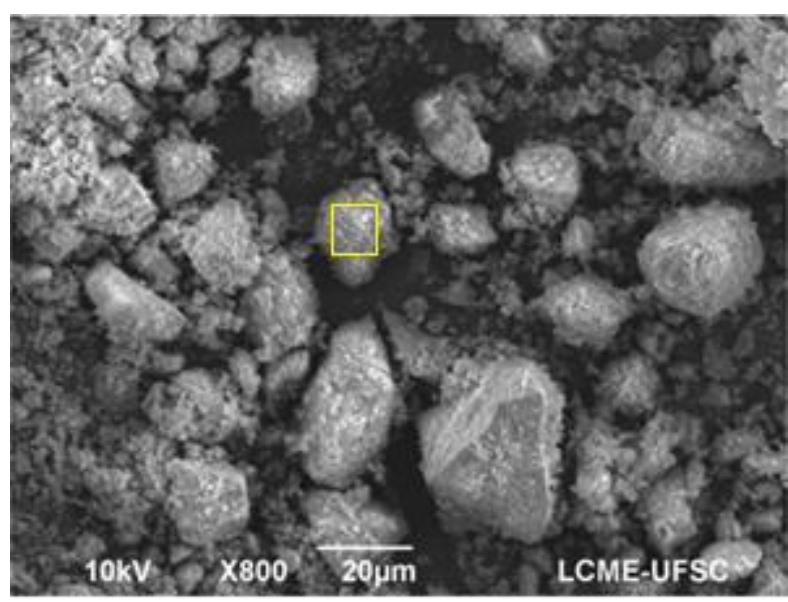

Tabela 6 - Porcentagem em massa obtida no ensaio de EDS do LETAC

\begin{tabular}{c|c|c|c|c|c|c|c}
\hline Átomos & $\mathbf{O}$ & $\mathbf{M g}$ & $\mathbf{A l}$ & $\mathbf{S i}$ & $\mathbf{K}$ & $\mathbf{C a}$ & $\mathbf{F e}$ \\
\hline$\%$ & 36,59 & 0,59 & 13,59 & 33,50 & 1,33 & 0,56 & 13,84 \\
\hline
\end{tabular}

Tabela 7 - Resultados dos ensaios realizados nas argamassas A e B e o percentual de aditivo superplastificante utilizado

\begin{tabular}{c|c|c|c|c|c|c|c}
\hline \multirow{2}{*}{ Argamassa } & \multicolumn{3}{|c|}{ IC (mm) } & \multicolumn{3}{c|}{ RC (Mpa) } & \multirow{2}{*}{ SP(\%) } \\
\cline { 2 - 7 } & Média & DV & CV & Média & DV & CV & \\
\hline A & 251 & 2,46 & 1,22 & 40,3 & 0,99 & 2,46 & - \\
B & 242 & 6,29 & 0,86 & 46,1 & 2,90 & 6,29 & 0,49 \\
\hline
\end{tabular}

Figura 5 - Influência da relação a/ag e do teor de LETAC no fluxo de calor

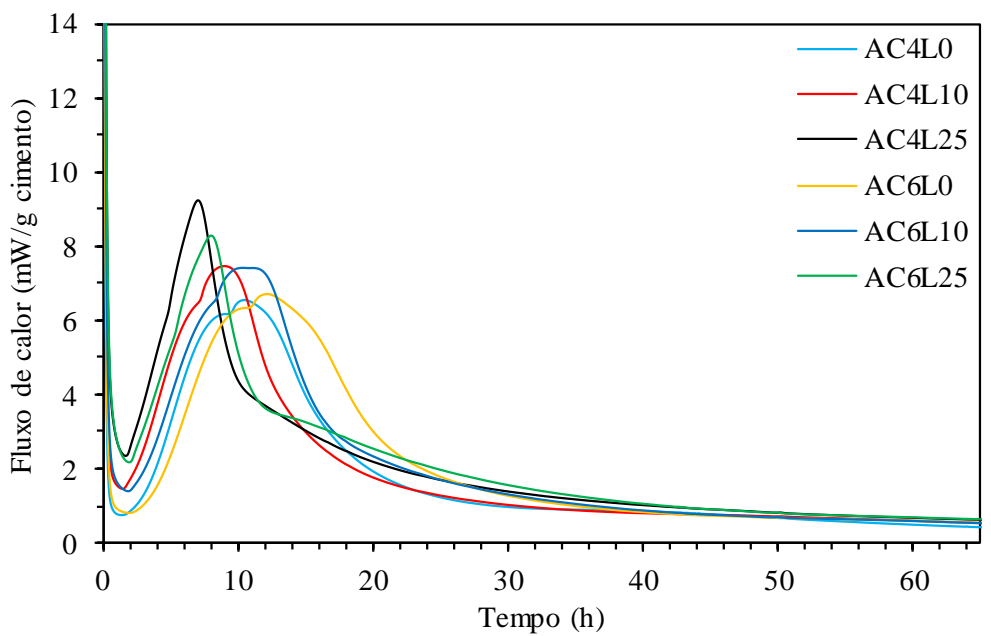

AFigura 5 mostra que uma diminuição na relação a/agaumenta a taxa de reação no período de dormência. Isso provavelmente ocorre devido à alta concentração de íons alcalinos que promovem a dissolução das fases anidras(DANIELSON, 1962). Entretanto, conforme se observa na Figura 6, o grau de hidratação em longo prazo diminui, uma vez que há menor quantidade de água disponível e menos espaço para o crescimento dos hidratos (LOTHENBACH; SCRIVENER; HOOTON, 2011). Assim como Abbas e Majdi (2017), conclui-se que o calor de hidratação aumenta quanto maior é a relação a/ag.

Conforme se observa na Figura 5, o aumento na concentração de LETAC aumentou o valor máximo do segundo pico de liberação de calor e deslocou o pico para menores tempos de hidratação. Esse aumento na 
evolução do calor durante o período de aceleração é consistente com um acréscimo de locais de nucleação, provocado pelas partículas adicionadas, acelerando a hidratação do cimento (LOTHENBACH; SCRIVENER; HOOTON, 2011). O efeito da nucleação heterogênea depende da quantidade de adição utilizada, uma vez que a probabilidade de os locais de nucleação estarem perto das partículas de cimento aumenta com a quantidade de adição (LAWRENCE; CYR; RINGOT, 2003). Isso significa que, para pastas com relações a/ag de 0,4 ou 0,6, a incorporação de LETAC em até $25 \%$ favorece o desenvolvimento da hidratação do cimento, evidenciando o efeito fíler desse resíduo nas idades iniciais. Além disso, nas pastas contendo LETAC, independentemente da relação a/c, o aumento na evolução do calor durante o período de aceleração é muito mais acentuado (maior inclinação do trecho que leva ao segundo pico), o que indica um efeito químico do LETAC (LOTHENBACH; SCRIVENER; HOOTON, 2011).

A Tabela 8 mostra os tempos, inicial e final, estimados para o período de indução de cada composição. Para o cálculo do período de indução, foi traçada uma reta no período de pré-indução e extrapolada a linha de regressão do período de aceleração da curva de fluxo de calor em função do tempo. O período de indução foi determinado pelas intersecções do trecho horizontal com essas duas retas, conforme Betioli (2007).

Verifica-se a partir da Tabela 8 que o fim do período de indução ocorre em menores tempos para misturas com maior teor de LETAC, confirmando que o início do período de aceleração é adiantado em misturas com maior concentração de LETAC.

Em um trabalho prévio, Stein (2016) comparou as curvas de liberação de calor e calor acumulado de amostras de pastas com diferentes teores de LETAC (5\%,10\%, 15\%, 20\%, 25\% e 30\%) com uma amostra padrão (100\% CPV ARI), com relação a/ag fixa de 0,5. Os resultados de Stein (2016) mostram que as amostras com maior percentual de LETAC apresentaram valores máximos inferiores no segundo pico e retardo no processo da hidratação. Tais resultados são contrários aos encontrados nesta pesquisa. Esse fato pode estar associado à diferença significativa entre a área específica, BET, do LETAC utilizado, uma vez que quanto maior a finura, mais rápida a taxa de desenvolvimento de calor de hidratação, provavelmente devido ao aumento dos locais de nucleação (LAWRENCE; CYR; RINGOT, 2003; KADRI et al., 2010). O resíduo utilizado nesta pesquisa apresenta uma área específica de cerca de duas vezes a área do resíduo utilizado por Stein (2016), que apresentou BET de $27,7 \mathrm{~m}^{2} / \mathrm{g}$.

Figura 6 - Influência da relação a/ag e do teor de LETAC no calor acumulado

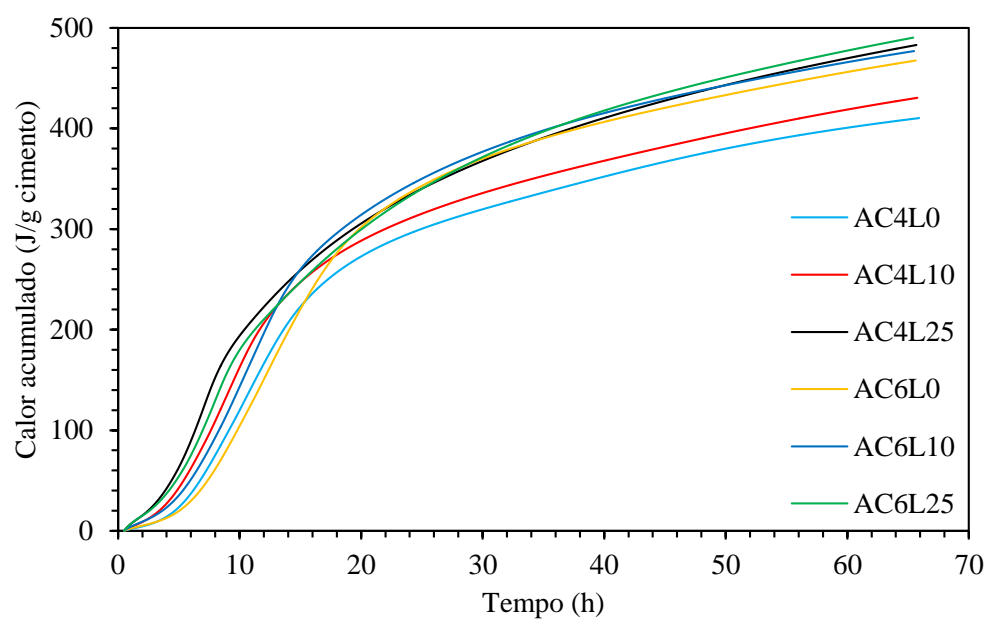

Tabela 8 - Período de indução estimado das pastas em função do teor de LETAC

\begin{tabular}{c|c|c|c}
\hline \multirow{2}{*}{ MISTURA } & \multicolumn{3}{|c}{ PERÍODO DE INDUCÃO } \\
\cline { 2 - 4 } & INÍCIO (MIN) & FINAL (MIN) & TOTAL (MIN) \\
\hline AC4L0 & 9,6 & 144,6 & 135,0 \\
AC4L10 & 10,2 & 106,8 & 96,6 \\
AC4L25 & 10,8 & 100,2 & 89,4 \\
AC6L0 & 11,4 & 183,0 & 171,6 \\
AC6L10 & 12,6 & 137,4 & 124,8 \\
AC6L25 & 12,6 & 120,6 & 108,0 \\
\hline
\end{tabular}


A Figura 6mostra que a substituição parcial do cimento Portland por LETAC aumentou o calor acumulado, provocado pelo efeito fíler do resíduo, que fornece locais adicionais de nucleação para as fases hidratadas. Ao final do período avaliado, para a relação a/ag de 0,4, a pasta AC4L0 apresentou calor acumulado de $410,28 \mathrm{~J} / \mathrm{g}$ de cimento, enquanto a pasta contendo $25 \%$ do resíduo (AC4L25) exibiu 482,94J/g de cimento, ou seja, um aumento de $17,71 \%$. Já para a relação a/ag de 0,6, a pasta AC6L0 apresentou calor acumulado de 467,50J/g de cimento, enquanto a pasta contendo 25\% do resíduo (AC6L25) exibiu 590,26J/g de cimento, correspondendo a um aumento de $26,26 \%$.

Uma contribuição adicional ao calor de hidratação pode ser relacionada com a participação dos materiais cimentícios suplementares nas reações de hidratação(SCRIVENER; SNELLINGS; LOTHENBACH, 2016). Contudo, ressalta-se que no primeiro dia a atividade pozolânica é pequena, e o efeito da nucleação heterogênea é predominante (LOTHENBACH; SCRIVENER; HOOTON, 2011).

\section{Análise termogravimétrica}

A Figura 7 apresenta os resultados da análise termogravimétrica e termogravimetria derivada das pastas de cimento Portland avaliadas neste estudo.

A partir dos valores de perda de massa associados à faixa de temperatura de $400{ }^{\circ} \mathrm{C}-500{ }^{\circ} \mathrm{C}$, foram calculados percentuais de hidróxido de cálcio de 28,69\%,21,15\% e 16,01\% para as amostras AC6L0, AC6L10 e AC6L25, respectivamente. Dessa maneira, foram observadas reduções no teor de hidróxido de cálcio de aproximadamente $26 \%$ e $44 \%$ para as amostras AC6L10 e AC6L25 em relação à referência (AC6L0).

Diante do exposto, verifica-se que o aumento do percentual de substituição do cimento Portland por LETAC promoveu uma redução no teor de hidróxido de cálcio das pastas. Esse comportamento pode ser atribuído ao consumo do $\mathrm{Ca}(\mathrm{OH})_{2}$ decorrente da atividade pozolânica do resíduo.

Nesse contexto, o consumo do hidróxido de cálcio também foi identificado em um trabalho prévio que avaliou a incorporação do LETAC em matrizes cimentícias. Stein (2016) realizou o ensaio de termogravimetria em pastas de cimento com relação a/ag de 0,65 e teores de substituição de $\mathrm{CP} \mathrm{V}-\mathrm{ARI}$ por LETAC (temperatura de calcinação de $600{ }^{\circ} \mathrm{C}$ ) de $5 \%, 10 \%, 15 \%$ e 20\%. Aos 28 dias o percentual de $\mathrm{Ca}(\mathrm{OH})_{2}$ da amostra de referência era de $21,30 \%$, enquanto que das amostras com teores de substituição de lodo de $10 \%$ e $20 \%$ eram de $18,50 \%$ e $14,11 \%$, correspondentes a reduções de $20,43 \%$ e $33,75 \%$, respectivamente. Dessa maneira, os resultados encontrados nesta pesquisa corroboram com os encontrados por Stein (2016), reforçando a atividade pozolânica do LETAC.

Figura 7 - Análise termogravimétrica (TGA) e termogravimetria derivada (DTG) das pastas AC6L0, AC6L10 e AC6L25

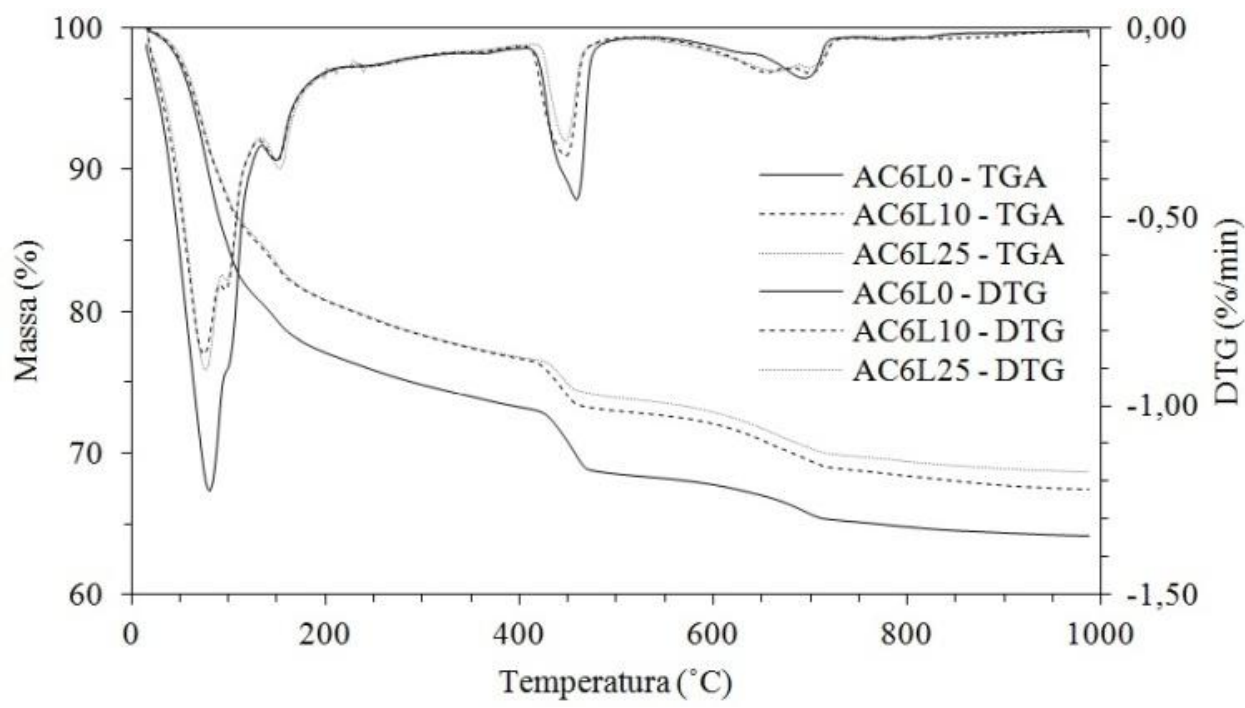


Visando à comparação da atividade pozolânica do lodo calcinado com materiais cimentícios suplementares usuais, como a sílica ativa, metacaulim e cinza da casca de arroz, são apresentados os resultados encontrados no trabalho de Hoppe Filho et al. (2017). Os autores moldaram pastas com substituição de 35\% do volume de cimento pelas adições minerais anteriormente citadas (equivalente a um teor de substituição em massa de $27,3 \%, 30,0 \%$ e 26,7\% para as misturas com sílica ativa, metacaulim e cinza de casca de arroz, respectivamente) e relações a/ag de 0,7 e avaliaram o teor de hidróxido de cálcio dessas misturas aos 28 dias pelo ensaio de termogravimetria. Os resultados encontrados indicaram uma redução do teor de hidróxido de cálcio de $85,3 \%, 72,3 \%$ e $62,3 \%$ em relação à referência para os traços com sílica ativa, metacaulim e cinza da casca de arroz. Desse modo, verifica-se que o LETAC possui uma eficiência inferior em relação aos materiais avaliados por Hoppe Filho et al. (2017).

\section{Difração de raios $\mathrm{X}$}

A análise de DRX foi realizada nas pastas de cimento Portland com relação a/ag de 0,6, após 28 dias. Foram quantificadas as fases amorfas de cada composição e os resultados são apresentadosna Tabela 9.

Corroborando com Snellings, Salze e Scrivener (2014), Juenger e Siddique (2015) e Stein (2016), a porcentagem de fases amorfas nas composições que continham o LETAC foi maior do que das amostras de referência. SegundoLothenbach, Scrivener e Hooton (2011), os SCMs, assim como o LETAC, tendem a promover o desenvolvimento adicional do $\mathrm{C}-\mathrm{S}-\mathrm{H}$, elevando o conteúdo amorfo da mistura, conforme observado nas composições contendo LETAC.

NaFigura 8 são apresentados os difratogramas das pastas AC6L0, AC6L10 e AC6L25, assim como a identificação das principais fases cristalinas presentes nesses materiais. Verifica-se uma redução dos picos de hidróxido de cálcio $(\mathrm{CH})$ com o aumento do teor de substituição de cimento por LETAC e um consequente aumento da intensidade dos picos de C-S-H, o que pode ser associado à atividade pozolânica do material cimentício suplementar em questão.

Nesse contexto, Stein (2016) também realizou o ensaio de DRX aos 28 dias, em pastas de cimento Portland de alta resistência inicial (CP V - ARI) com diferentes relações a/c e com substituição do cimento por LETAC nos teores de $5 \%, 10 \%, 15 \%$ e $20 \%$. O autor observou que quanto maiores os teores de LETAC, menores foram os picos de hidróxido de cálcio, já que esse se combina com a sílica presente no material, favorecendo as reações pozolânicas, aumentando a produção de $\mathrm{C}-\mathrm{S}-\mathrm{H}$, o que também ocorreu no presente estudo.

Tabela 9 - Quantificação das fases amorfas de todas as composições ensaiadas

\begin{tabular}{c|c|c|c}
\hline AMOSTRA & AC6L0 & AC6L10 & AC6L25 \\
\hline Percentual de fases amorfas & $57 \%$ & $64 \%$ & $63 \%$ \\
\hline
\end{tabular}

Figura 8 - Difratograma das pastas AC6L0, AC6L20 e AC6L25 aos 28 dias de idade (Et - Etringita; CH hidróxido de cálcio; C-S-H - silicato de cálcio hidratado)

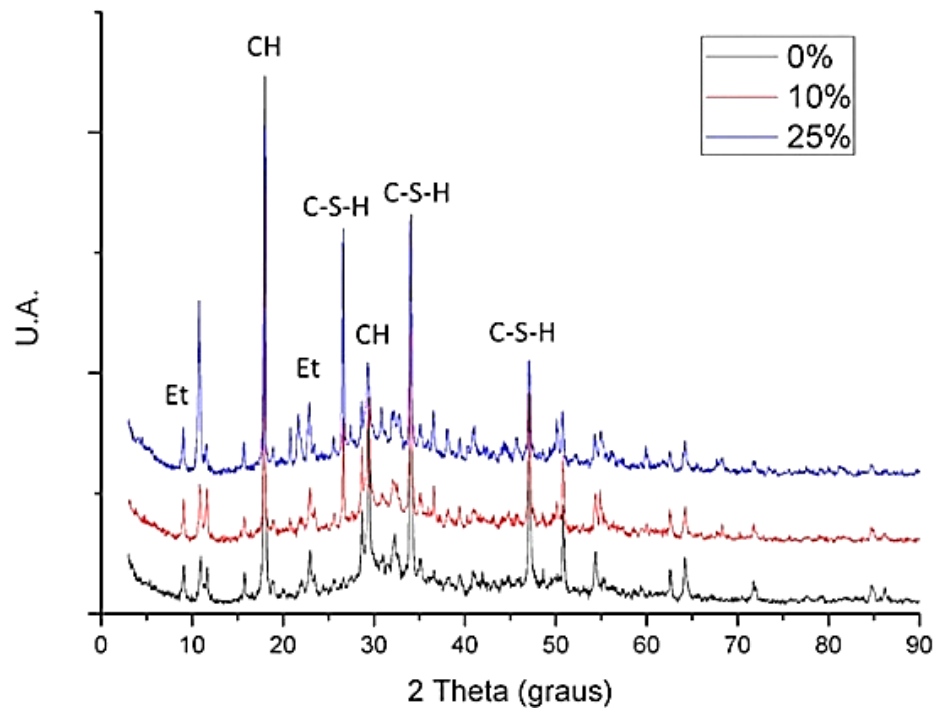




\section{Microscopia eletrônica de varredura}

No ensaio de microscopia eletrônica de varredura (MEV) foram extraídas 30 imagens para cada amostra analisada. A Figura 9(a) corresponde às imagens selecionadas da pasta de cimento de referência (AC6L0), em que se destaca a porosidade da mistura e a evidente formação de hidróxido de cálcio e etringita. A micrografia da pasta de cimento com adição de 25\% do resíduo da ETA (AC6L25) é apresentada na Figura 9(b). Observa-se uma relevante homogeneidade da matriz e presença das partículas do lodo, possível diminuição da porosidade em relação à pasta de referência e, principalmente, ausência de cristais de $\mathrm{C}-\mathrm{H}$ (hidróxido de cálcio).

A Tabela 10 mostra os resultados da EDS das regiões delimitadas na Figura 9. É possível verificar que a pasta de cimento de referência apresentou um elevado teor de cálcio, indicando a formação de $\mathrm{Ca}(\mathrm{OH})_{2}$ e CS-H. Já para a amostra AC6L25, identificou-se um aumento da concentração de sílica e alumínio, aliado a uma redução considerável de cálcio em relação à referência, o queindica, qualitativamente, que o LETAC apresenta atividade pozolânica e consome o hidróxido de cálcio. $\mathrm{O} \mathrm{Ca}(\mathrm{OH})_{2}$ possivelmente reage com a sílica e alumina contida no resíduo, corroborando com outros estudos que indicaram a ocorrência da atividade pozolânica com o uso desse resíduo, comoEl-Didamony, Khalil e Heikal (2014), Frías et al.(2014) e El-Didamony, Mohammed e Osman (2015).

\section{Índice de consistência}

O índice de consistência das argamassas AC6L0, AC6L10 e AC6L25 foram de, respectivamente, $299 \mathrm{~mm}$, $305 \mathrm{~mm}$ e $297 \mathrm{~mm}$, conforme Tabela 11. Estatisticamente, as três composições apresentaram índices de consistência iguais. Dessa forma, não foi necessário o uso de aditivos para manter o índice de consistência das argamassas com LETAC iguais a da argamassa de referência.

Figura 9 - Micrografias das pastas(a) AC6L0 e (b) AC6L25

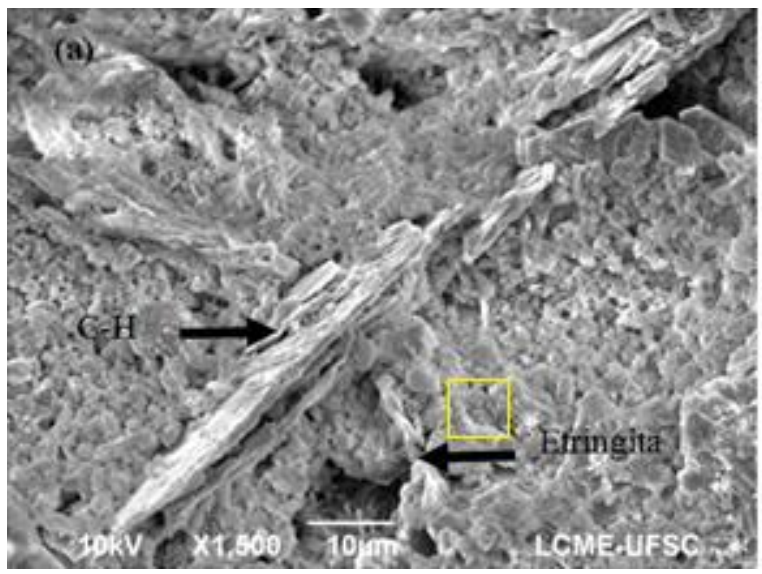

(a)

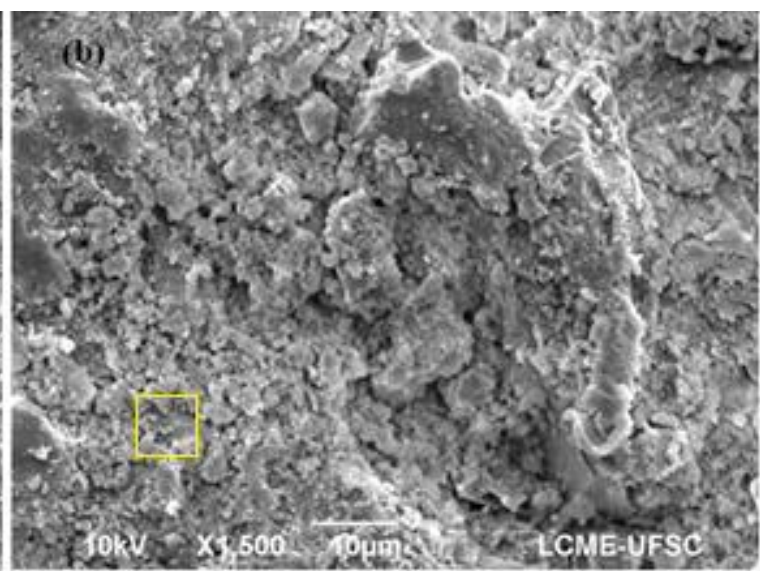

(b)

Tabela 10 - Porcentagem em massa obtida no EDS da pasta de cimento de referência (AC6L0) e da pasta com adição de $25 \%$ de LETAC (AC6L25)

\begin{tabular}{c|c|c|c|c|c|c}
\hline AMOSTRA & $\mathbf{C}(\boldsymbol{\%})$ & $\mathbf{O}(\mathbf{\%})$ & AL (\%) & SI (\%) & K (\%) & CA (\%) \\
\hline AC6L0 & 11,96 & 27,40 & 1,10 & 4,90 & 1,61 & 52,87 \\
AC6L25 & 16,24 & 27,58 & 2,72 & 11,07 & 2,61 & 39,78 \\
\hline
\end{tabular}

Tabela 11 - Índice de consistência das argamassas

\begin{tabular}{c|c|c|c|c|c|c}
\hline Argamassa & $\begin{array}{c}\text { Diâmetro 1 } \\
(\mathbf{m m})\end{array}$ & $\begin{array}{c}\text { Diâmetro 2 } \\
(\mathbf{m m})\end{array}$ & $\begin{array}{c}\text { Diâmetro 3 } \\
(\mathbf{m m})\end{array}$ & Média & DV & CV (\%) \\
\hline AC6L0 & 298 & 299 & 301 & 299 & 1,53 & 0,511 \\
AC6L10 & 305 & 303 & 307 & 305 & 2,00 & 0,656 \\
AC6L25 & 297 & 293 & 298 & 297 & 2,65 & 0,891 \\
\hline
\end{tabular}




\section{Ensaios mecânicos}

Os resultados de resistência à compressão das pastas e argamassas são apresentados na Figura 10. Verificase que houve uma redução na resistência das argamassas AC6L10 e AC6L25 em relação à referência AC6L0 de $13,2 \%$ e $15,5 \%$, respectivamente. Já para as pastas de cimento Portland, a resistência à compressão da mistura AC6L10 manteve-se igual à referência, enquanto que para o traço AC6L25 foi identificada uma redução de apenas $8 \%$.

A análise de variância dos resultados de resistência à compressão das pastas e argamassas é apresentada na Tabela 12. Como pode ser observado, o teor de LETAC exerce influência significativa na resistência à compressão das argamassas, diferentemente do observado para as pastas de cimento Portland. Adicionalmente, foi realizada a comparação de médias de resistência à compressão dos diferentes teores de lodo de ETA calcinado para verificar se existem diferenças estatisticamente significativas entre as composições avaliadas nesta pesquisa. Os resultados obtidos indicaram que, para as argamassas, o traço de referência (AC6L0) apresentou diferença estatisticamente significativa em relação aos traços AC6L10 e AC6L25, os quais podem ser considerados estatisticamente iguais. Já em relação às pastas de cimento Portland, verificou-se que as três composições não apresentaram diferenças significativas quanto à resistência à compressão, o que indica que não há perda de resistência quando o resíduo é incorporado às misturas nas concentrações testadas.

Figura 10 - Resistência à compressão axial aos 28 dias das argamassas e pastas com a/ag=0,6

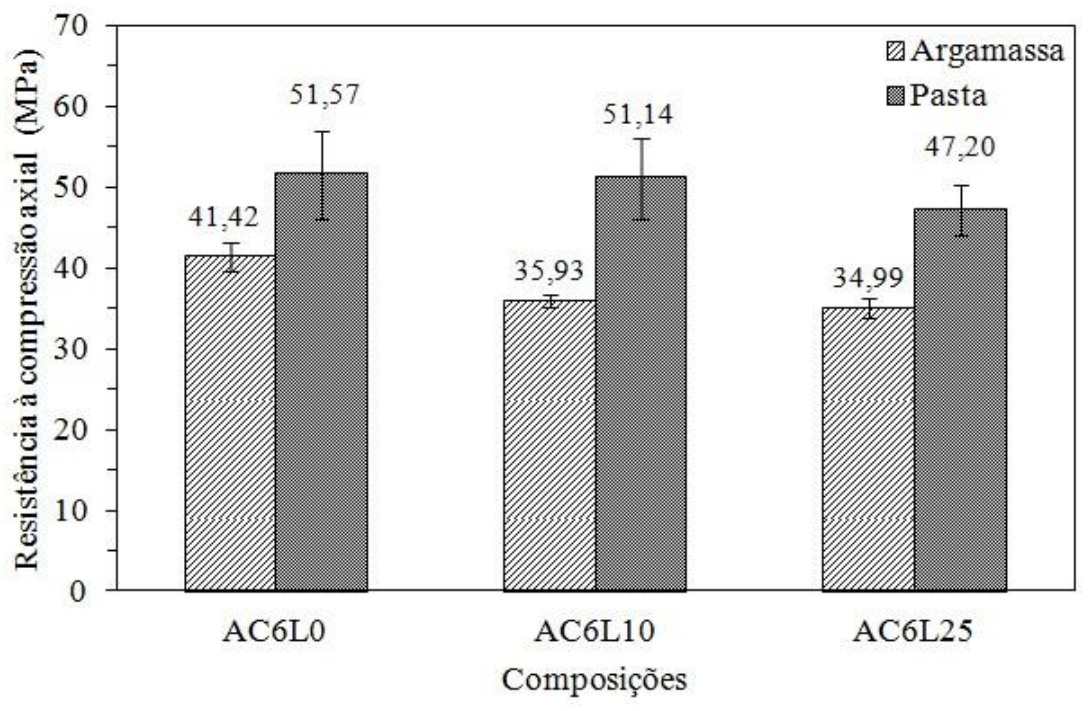

Tabela 12 - Análise de variância (ANOVA) dos resultados de resistência à compressão das pastas e argamassas

\begin{tabular}{|c|c|c|c|c|c|c|c|}
\hline $\begin{array}{c}\text { Matriz } \\
\text { cimentícia }\end{array}$ & Variável & SQ & GDL & MQ & Teste F & p-value & Influência \\
\hline Argamassa & $\begin{array}{l}\text { Teor de lodo } \\
\text { Erro } \\
\end{array}$ & $\begin{array}{c}120,59 \\
20,39 \\
\end{array}$ & $\begin{array}{c}2 \\
12 \\
\end{array}$ & $\begin{array}{c}60,29 \\
1,7 \\
\end{array}$ & $\begin{array}{c}35,48 \\
-\end{array}$ & $\begin{array}{c}0,000009 \\
-\end{array}$ & $\begin{array}{c}\text { significativa } \\
-\end{array}$ \\
\hline Pasta & $\begin{array}{l}\text { Teor de lodo } \\
\text { Erro }\end{array}$ & $\begin{array}{c}58,18 \\
256,84\end{array}$ & $\begin{array}{c}2 \\
12\end{array}$ & $\begin{array}{c}29,09 \\
21,4\end{array}$ & $\begin{array}{c}1,359 \\
-\end{array}$ & $\begin{array}{c}0,293711 \\
-\end{array}$ & $\begin{array}{c}\text { Não } \\
-\end{array}$ \\
\hline
\end{tabular}

Nota: Legenda:

SQ - soma dos quadrados;

GDL - graus de liberdade; e

MQ - média dos quadrados. 
Nesse contexto, os resultados de resistência à compressão das pastas podem ser correlacionados com os ensaios microestruturais previamente apresentados. Isso porque, de fato, verificou-se uma redução da quantidade de cristais de portlandita nas micrografias (Figura 9) das pastas contendo LETAC, provavelmente devido à reação pozolânica do resíduo, conforme também observado nos ensaios de termogravimetria e difração de raios $\mathrm{X}$, uma vez que se identificou o consumo do hidróxido de cálcio e consequente formação adicional de C-S-H. Isso justifica o desempenho mecânico equivalente das pastas AC4L10 e AC4L25 em comparação à pasta de referência, visto que, embora possuam uma quantidade de cimento Portland inferior, ainda assim, em decorrência da ação pozolânica do resíduo avaliado, apresentaram resistências à compressão estatisticamente iguais à pasta AC4L0.

Nesse contexto, considerando que a ação física do LETAC, verificada nas curvas da calorimetria, tem influência predominante sobre a hidratação do cimento nas idades iniciais, acredita-se que o desenvolvimento da resistência em idades mais avançadas seja decorrente da ação pozolânica do material. Dessa forma, neste estudo, algumas formulações contendo LETAC apresentaram resistências à compressão aos 28 dias ligeiramente menores com relação às resistências das amostras referência, o que pode ser atribuído à lentidão das reações pozolânicas.

Os valores médios de resistência à tração na flexão obtidos para cada argamassa são apresentados na Figura 11. Os resultados obtidos na ANOVA são apresentados na Tabela 13. Como pode ser observado, o teor de LETAC exerce influência significativa na resistência à tração na flexão. Já os resultados da comparação de média entre as composições avaliadas indicaram que, estatisticamente, todos os resultados de resistênciapodem ser considerados iguais, exceto quando comparados os traços AC6L10 e AC6L25, em que foi verificada uma diferença de aproximadamente $22 \%$. Sendo assim, a substituição de até $10 \%$ de cimento por LETACpode ser realizada sem perdas significativas nas resistências à tração na flexão.

\section{Conclusões}

Este estudo avaliou o comportamento de pastas e argamassas com a incorporação de diferentes percentuais de lodo de ETA calcinado proveniente de uma estação de tratamento localizada no município de Venâncio Aires como material cimentício suplementar.

Figura 11 - Resistência à tração na flexão das argamassas aos 28 dias

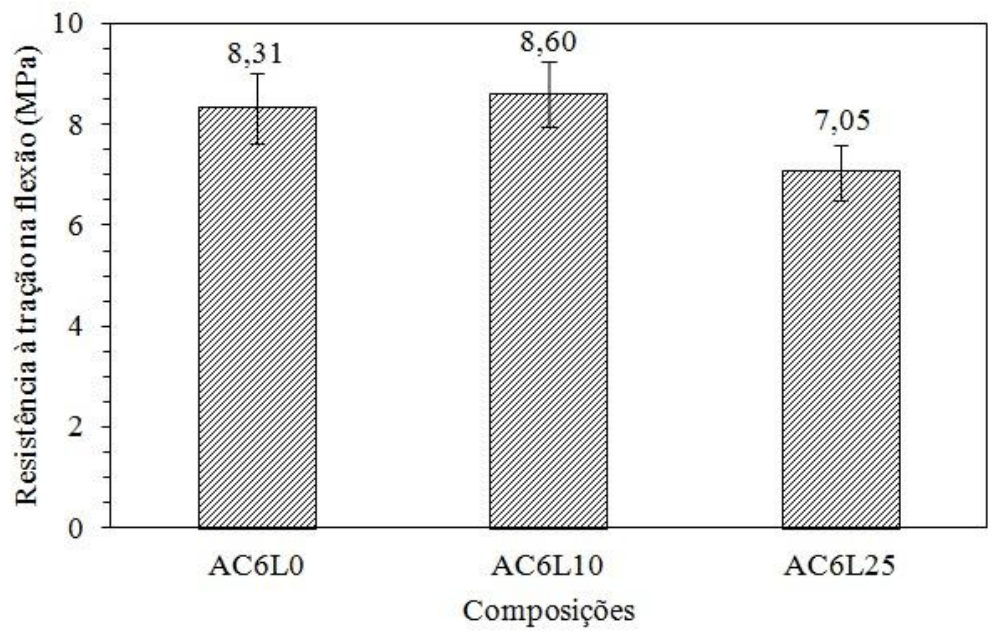

Tabela 13 - Análise de variância (ANOVA) dos resultados de resistência à tração na flexão das argamassas aos 28 dias

\begin{tabular}{c|c|c|c|c|c|c}
\hline Variável & SO & GDL & MQ & Teste F & p-value & Influência \\
\hline Teor de lodo & 4,0754 & 2 & 2,0377 & 5,125 & 0,050343 & significativa \\
Erro & 2,3857 & 6 & 0,3976 & - & - & - \\
\hline
\end{tabular}

Nota: Legenda:

SQ - soma dos quadrados;

GDL - graus de liberdade; e

MQ - média dos quadrados. 
Com relação à incorporação desse resíduo em matrizes cimentícias, o ensaio de calorimetria isotérmica indicou que o aumento do teor de lodo de ETA calcinado incorporado às pastas aumentou o pico de liberação de calor durante o período de aceleração, deslocou o pico para menores tempos de hidratação e aumentou o calor acumulado. Esse aumento na evolução do calor é consistente com um acréscimo de locais de nucleação dos hidratos. Além disso, o aumento na evolução do calor durante o período de aceleração foi mais acentuado em pastas contendo LETAC, indicando um efeito químico do LETAC.

Os resultados da análise termogravimétrica e de difração de raiosX indicaram que a incorporação de lodo de ETA calcinado nas pastas de cimento promoveu um consumo de hidróxido de cálcio e consequente formação de C-S-H. O percentual de $\mathrm{Ca}(\mathrm{OH})_{2}$ das amostras AC6L0, AC6L10 e AC6L25 foi de aproximadamente $28,69 \%, 21,15 \%$ e $16,01 \%$, respectivamente. Além disso, a quantidade de fases amorfas das pastas com teores de $10 \%$ e $25 \%$ de LETAC foram superiores à da amostra de referência, confirmando o desenvolvimento adicional de C-S-H em misturas com MCS na composição. Tais resultados corroboram com a análise qualitativa das micrografias da pasta de referência e com incorporação de $25 \%$ de lodo de ETA calcinado.

Quanto às propriedades mecânicas, foi possível viabilizar a incorporação de lodo de ETA calcinado em misturas cimentícias. Para a resistência à compressão axial, é possível a substituição de até $25 \%$ de cimento Portland por LETACsem perdas significativas na resistência das pastas. Considerando a resistência à tração na flexão das argamassas, foi possível a substituição de até $10 \%$ sem perdas.

Considerando o exposto, o lodo de ETA calcinado apresenta grande potencial para utilização como MCS e pode ser incorporado em pastas e argamassas de cimento Portland sem comprometer o desempenho mecânico de tais matrizes cimentícias. Dessa maneira, destaca-se que o resíduo em questão pode contribuir para a redução do impacto ambiental decorrente da indústria do cimento e para o desenvolvimento mais sustentável da construção civil. Por fim, reitera-se a importância do estudo em questão no que tange à caracterização de lodos de ETA de diferentes procedências com o intuito de viabilizar a produção de materiais cimentícios suplementares a partir de tal resíduo em escala comercial e a incorporação desse material em matrizes cimentícias sem comprometer as propriedades mecânicas e de durabilidade.

\section{Referências}

ABBAS, Z. H.; MAJDI, H. S. Study of heat of hydration of Portland cement used in Iraq. Case studies in construction materials, v. 7, p. 154-162, 2017.

AHMAD, T.; AHMAD, K.; ALAM, M. Sustainable management of water treatment sludge through 3'R' concept. Journal of Cleaner Production, v. 124, p. 1-13, 2016.

AMERICAN SOCIETY FOR TESTING AND MATERIALS. C-1231: standard practice for use of unbonded caps in determination of compressive strength of hardened concrete cylinders. Pennsylvania, 2010.

AMERICAN SOCIETY FOR TESTING AND MATERIALS. C150/C150M: standard specification for Portland cement. Pennsylvania, 2018.

ASSOCIAÇÃO BRASILEIRA DE NORMAS TÉCNICAS. NBR 10004: resíduos sólidos: classificação. Rio de Janeiro, 2004.

ASSOCIAÇÃO BRASILEIRA DE NORMAS TÉCNICAS. NBR 12653: materiais pozolânicos: requisitos. Rio de Janeiro, 2015a.

ASSOCIAÇÃO BRASILEIRA DE NORMAS TÉCNICAS. NBR 13279: argamassas para assentamento e revestimento de paredes e tetos: determinação da resistência à tração na flexão e à compressão. Rio de Janeiro, 2005.

ASSOCIAÇÃO BRASILEIRA DE NORMAS TÉCNICAS. NBR 16697: cimento Portland: requisitos. Rio de Janeiro, 2018.

ASSOCIAÇÃO BRASILEIRA DE NORMAS TÉCNICAS. NBR 5752: materiais pozolânicos: determinação do índice de desempenho com cimento Portland aos 28 dias. Rio de Janeiro, 2014.

ASSOCIAÇÃO BRASILEIRA DE NORMAS TÉCNICAS. NBR 7214: areia normal para ensaio de cimento: especificação. Rio de Janeiro, 2015b. 
ASSOCIAÇÃO BRASILEIRA DE NORMAS TÉCNICAS. NBR 7215: cimento Portland: determinação da resistência à compressão. Rio de Janeiro, 2019.

BERNARDO, L.; DANTAS, A.; VOLTAN, P. E. N. Métodos e técnicas de tratamento dos resíduos gerados em estações de tratamento de água. São Carlos: LDiBe Editora, 2012.

BERODIER, E.; SCRIVENER, K. Evolution of pore structure in blended systems. Cement and Concrete Research, v. 73, p. 25-35, 2015.

BETIOLI, A. M. Influência dos polímeros MHEC e EVA na hidratação e comportamento reológico de pastas de cimento Portland. Florianópolis, 2007.Tese (Doutorado) - Programa de Pós-Graduação em Engenharia Civil, Universidade Federal de Santa Catarina, Florianópolis, 2007.

COCCO, M. Resistividade elétrica de concretos compostos com cinza de lodo de ETA e calcário moído. Santa Maria, 2017. Dissertação (Mestrado em Engenharia Civil) - Programa de Pós-Graduação em Engenharia Civil, Universidade Federal de Santa Maria, Santa Maria, 2017.

DANIELSON, U. H. Heat of hydration of cement as affected by water-cement ratio. In: INTERNATIONAL SYMPOSIUM ON THE CHEMISTRY OF CEMENT, 4., Washington DC, 1962. Proceedings [...] Washington DC, 1962.

EL-DIDAMONY, H.; KHALIL, K. A.; HEIKAL, M. Physico-chemical and surface characteristics of some granulated slag-fired drinking water sludge composite cement pastes. HBRC Journal, v. 10, n. 1, p. 73-81, 2014.

EL-DIDAMONY, H.; MOHAMMED, M. S.; OSMAN, R. M. Effect of substitution of blast-furnace slag by fired drinking water sludge on the properties of pozzolanic cement pastes. Journal of Thermal Analysis and Calorimetry, v. 122, p. 81-88, 2015.

FRÍAS, M. et al. Influence of activated drinking-water treatment waste on binary cement-based composite behavior: characterization and properties. Composites: Part B, v. 60, p. 14-20, 2014.

GASTALDINI, A. L. G. et al. The use of water treatment plant sludge ash as a mineral addition.Construction and Building Materials, v. 95, p. 513-520, 2015.

GODOY, L. G. G. et al. Valorization of water treatment sludge waste by application as supplementary cementitious material. Construction and Building Materials, v. 223, pp. 939-950, 2019.

GOMES, S. C. et al. Progress in manufacture and properties of construction materials incorporating water treatment sludge: A review. Resources, Conservation and Recycling, v. 145, p. 148-159, 2019.

HAGEMANN, S. E. et al. Synergic effects of the substitution of Portland cement for water treatment plant sludge ash and ground limestone: Technical and economic evaluation. Journal of Cleaner Production, v. 214, p. 916-926, 2019.

HOPPE FILHO, J. et al. Atividade pozolânica de adições minerais para cimento Portland (Parte II): Índice de atividade pozolânica com cimento Portland (IAP), difração de raios-X (DRX) e termogravimetria (TG/DTG). RevistaMatéria, v. 22, n. 3, p. 1-19, 2017.

JUENGER, M.C. G.; SIDDIQUE, R. Recent advances in understanding the role of supplementary cementitious materials in concrete. Cement and Concrete Research, v. 78, p. 71-80, 2015.

KADRI, E. H. et al. Combined effect of chemical nature and fineness of mineral powders on Portland cement hydration. Materials and Structures, v. 43, n 5, p. 665-673, 2010.

KIZINIEVIČ, O. et al. Utilisation of sludge waste from water treatment for ceramic products. Construction and Building Materials, v. 41, p. 464-473, 2013.

LAFARGEHOLCIM. Relatório de ensaios de cimento. Minas Gerais, set. 2018.

LAWRENCE, P.; CRY, M.; RINGOT, E. Mineral admixtures in mortars: effect of inert materials on shortterm hydration. Cement and Concrete Research, v. 33, n. 12, p. 1939-1947, 2003.

LOTHENBACH, B.; SCRIVENER, K.; HOOTON, R. D. Supplementary cementitious materials. Cement and Concrete Research, v. 41, n 12, p. 1244-1256, 2011.

MONTEIRO, S. N. et al. Incorporation of sludge waste from water treatment plant into red ceramic. Construction and Building Materials, v. 22, n, 6, p. 1281-1287, 2008. 
NIMWINYA, E. et al. A sustainable calcined water treatment sludge and rice husk ash geopolymer. Journal of Cleaner Production, v. 119, p. 128-134, 2016.

RODRÍGUEZ, N. H. et al. Re-use of drinking water treatment plant (DWTP) sludge: characterization and technological behaviour of cement mortars with atomized sludge additions. Cement and Concrete Research, v. 40, n. 5, p. 778-786, 2010.

SCRIVENER, K.; SNELLINGS, R.; LOTHENBACH, B. A practical guide to microstructural analysis of cementitious materials. Bota Raton: CRC Press, 2016.

SNELLINGS, R.; SALZE, A.; SCRIVENER, K. L. Use of X-ray diffraction to quantify amorphous supplementary cementitious materials in anhydrous and hydrated blended cements. Cement and Concrete Research, v. 64, p. 89-98, 2014.

STEIN, R. T. Características de pastas de cimento Portland com adição de cinza de lodo de ETA. Santa Maria, 2016. Dissertação (Mestrado em Engenharia Civil) - Programa de Pós-Graduação em Engenharia Civil, Universidade Federal de Santa Maria, Santa Maria, 2016.

TARTARI, R. Incorporação de lodo gerado na estação de tratamento de água tamanduá, como aditivo em massas para cerâmica vermelha. Cascavel, 2008. Dissertação (Mestrado em Engenharia Química) Programa de Pós-Graduação em Engenharia Química, Universidade Estadual do Oeste do Paraná, Cascavel, 2008.

TIRONI, A. et al. Assessment of pozzolanic activity of different calcined clays. Cement and Concrete Composites, v. 37, p. 319-327, 2013.

\title{
WORLD BUSINESS COUNCIL FOR SUSTAINABLE DEVELOPMENT. GNR PROJECT Reporting CO . Geneva, 2016.
}

\section{Agradecimentos}

Os autores agradecem ao Laboratório de Aplicações de Nanotecnologia em Construção Civil (NANOTECLAB),Laboratório Central de Microscopia Eletrônica (LCME) e ao Laboratório de Materiais de Construção Civil (LMCC)peloapoio técnico.Agradecemà Capes pelo apoio, referente ao Edital Pró-Equipamento n. 04/2014, que possibilitou a realizaçãodo ensaio de fluorescência de raiosX. Por fim,agradecem à Capes e ao CNPq pela provisão das bolsas de mestrado edoutorado dos autores.

\section{Artur Spat Ruviaro}

Laboratório de Aplicações de Nanotecnologia em Construção Civil | Universidade Federal de Santa Catarina | Rua João Pio Duarte Silva, s/n, sala 406B | Florianópolis - SC - Brasil | CEP 88040-900 | Tel.: (48) 3721-4980 | E-mail: arturspatruviaro@gmail.com

\section{Laura Silvestro}

Laboratório de Aplicações de Nanotecnologia em Construção Civil | Universidade Federal de Santa Catarina | E-mail: laurasilvestro@ymail.com

Taylana Piccinini Scolaro

Departamento de Engenharia Civil | Universidade Federal de Santa Catarina | Rua João Pio Duarte Silva, s/n | Florianópolis - SC - Brasil | CEP 88040-900 | E-mail: taylanaps@hotmail.com

\section{Fernando Pelisser}

Departamento de Engenharia Civil | Universidade Federal de Santa Catarina | Rua João Pio Duarte Silva, s/n, sala 303A | Florianópolis SC - Brasil | CEP 88040-900 | Tel.: (3721-7765 | E-mail: pelisser@hotmail.com

\section{Philippe Jean Paul Gleize}

Departamento de Engenharia Civil | Universidade Federal de Santa Catarina | Rua João Pio Duarte Silva, s/n, sala 406B | Florianópolis SC - Brasil | CEP 88040-900 | Tel.: (48) 3721-4980 | E-mail: p.gleize@ufsc.br

\author{
Ambiente Construído \\ Revista da Associação Nacional de Tecnologia do Ambiente Construído \\ Av. Osvaldo Aranha, $99-3^{\circ}$ andar, Centro \\ Porto Alegre - RS - Brasil \\ CEP $90035-190$ \\ Telefone: +55 (51) 3308-4084 \\ Fax: +55 (51) 3308-4054 \\ www.seer.ufrgs.br/ambienteconstruido \\ E-mail: ambienteconstruido@ufrgs.br
}

